\title{
Infecções sexualmente transmissíveis e as vivências de mulheres em situação de reclusão
}

\author{
Sexually transmitted infections and the experiences of women in situations of imprisonment \\ Infecciones de transmisión sexual y las experiencias de las mujeres en situación de aislamiento
}

\author{
Márcia Astrês Fernandes'; Myrna Mayra Bezerra"; Fernanda Maria de Jesus Sousa Pires de Moural'I, \\ Nadyelle Elias Santos Alencar'v; Francisca Fabiana Fernandes Limav'; Augusto Everton Dias Castro ${ }^{\text {VI }}$
}

\begin{abstract}
RESUMO
Objetivos. conhecer os riscos que caracterizam as detentas como um grupo susceptível a infecções sexualmente transmissíveis (IST); revelar as reações frente ao diagnóstico; e discutir a importância do aconselhamento em saúde. Método: pesquisa descritiva com abordagem qualitativa, realizada em uma penitenciária feminina de Teresina/Piauí, com nove presidiárias portadoras de IST/ Síndrome da Imunodeficiência Adquirida (AIDS). A coleta de dados, realizada com entrevista semiestruturada, ocorreu entre agosto e setembro de 2010. Os depoimentos foram gravados, transcritos e realizada análise de conteúdo. Estudo aprovado pelo Comitê de Ética da Universidade Federal do Piauí, CAEE: 4891.0.000.044-10. Resultados: o uso de drogas ilícitas, múltiplos parceiros sexuais e sexo desprotegido foram os comportamentos de risco mais frequentes para IST/AIDS. Diante do diagnóstico, as reações foram marcadas por tristeza, medo, receio do julgamento/rejeição familiar, raiva e barganha. Além disso, o aconselhamento em saúde é indispensável ao enfrentamento destas infecç̃os. Conclusão: aconselhamento de enfermagem e suporte emocional são ferramentas decisivas na ocasião do diagnóstico de uma IST/AIDS. Palavras-chave: Doenças sexualmente transmissíveis; prisioneiros; intervenção na crise; enfermagem.
\end{abstract}

\section{ABSTRACT}

Objective: to know the risks that characterize women prisoners as a susceptible group to sexually transmitted infections-(STI), to reveal the reactions to the diagnosis and to discuss the importance of health counselling. Method: descriptive research with qualitative approach. It occured in a feminine prison-Teresina/Piauí, with nine women prisoners living with STI/AIDS. The data collection, with a semi-structured form, was carried out between August-September of 2010. The interviews were recorded, transcripted and the content analysis was made. This study was approved by the Research Ethics Committee of the Federal University of Piauí, (CAAE No 4891.0.000.044-10). Results: use of illicit drugs, multiple sexual partners and unprotected sex were the most frequent risk behaviours. Facing the diagnosis, the reactions were sadness, scare, fear of family judgment/rejection, anger and bargain. Moreover, the health counselling is indispensable to cope with these infections. Conclusion: nursing counselling and emotional support are decisive tools when there is a STI/AIDS diagnmosis. Keywords: Sexually transmitted diseases; prisoners; crisis interventions; nursing.

\section{RESUMEN}

Objetivo: conocer los riesgos que caracterizan a las reclusas como un grupo susceptible a infecciones de transmisión sexual (ITS), revelar acciones frente a el diagnóstico y discutir la importancia de la asesoría en salud. Método: investigación descriptiva con enfoque cualitativo. Se llevó a cabo en un centro penitenciario femenino -Teresina/Piauí, con nueve presidiarias con diagnóstico de IST/AIDS. La recogida de datos fué realizada con formulario semi-estructurado, entre agosto y septiembre de 2010. Las entrevistas fueron grabadas, despues se realizó transcripción y análisis de contenido. Estudio aprobado por el Comité de Ética da Universidad Federal de Piauí, CAAE: 4891.0.000.044-10. Resultados: uso de drogas ilícitas, múltiplas parejas sexuales y relaciones sexuales sin protección fueron los comportamientos de riesgo más frecuentes para el IST/AIDS. Con el diagnóstico, las reacciones se caracterizaron por tristeza, miedo, miedo de rechazo/juicio de la familia, la ira y la negociación. Además, consejos sobre la salud son esenciales para la lucha contra estas infecciones. Conclusíon: asesoría de enfermería y apoyo emocional son herramientas claves en el momento del diagnóstico de una ITS/AIDS. Palabras clave: Enfermedades de transmisión sexual; prisioneiros; intervención en la crisis; enfermeira.

\section{INTRODUÇÃo}

A população carcerária brasileira ocupa o quarto lugar mundial com maior número absoluto de presos (622.202). Além disso, ao contrário de outros países, este número continua a crescer, principalmente entre as mulheres (10,7\% ao ano). Ressalta-se que os presídios brasileiros estão aquém da necessidade, com superlotação e um sistema organizacional que viola o direito dos que estão privados de liberdade ${ }^{1}$.

'Enfermeira. Doutora em Ciências pela Universidade de São Paulo. Professora Associada da Universidade Federal do Piauí. Teresina, Piauí, Brasil. E-mail: m.astres@ufpi.edu.br "Especialista em Terapia Intensiva. Enfermeira assistente no Hospital de Clínicas da Universidade Federal do Triângulo Mineiro. Uberaba, Minas Gerais, Brasil. E-mail: myrnabezerra@hotmail.com

"'Enfermeira. Mestre em Enfermagem pela Universidade Federal do Piauí. Professora Assistente da Universidade Federal do Piauí. Teresina, Piauí, Brasil. E-mail: fernandasousav@bol.com.br

IVEnfermeira. Mestranda em Enfermagem,Universidade Federal do Piauí. Teresina, Piauí, Brasil. E-mail: nadyelle-elias@hotmail.com

`Enfermeira. Mestranda em Enfermagem,Universidade Federal do Piauí. Teresina, Piauí, Brasil.E-mail: ffabiana-fl@hotmail.com

vIMestrando em Educação,Universidade Internacional Iberoamericana. Departamento de Pós-Graduação, Arecibo, Puerto Rico-EUA. E-mail: augusto.everton@ @otmail.com 
Além disso, os presos estão associados a comportamentos de risco, tanto antes como durante o encarceramento. A exemplo, as práticas sexuais inseguras são frequentes nessa população e, em consequência, as infecções sexualmente transmissíveis (IST) tornam-se cada vez mais comuns ${ }^{2}$.

IST, desde 2015, passou a ser a terminologia adotada pelo Ministério da Saúde em substituição à doença sexualmente transmissível (DST), em consonância com recomendações globais. Tal mudança visa desmitificar a ideia de que toda IST necessariamente manifesta sintomas. Muitas delas podem ser assintomáticas e, portanto, alimentam a cadeia de transmissão da infecção ${ }^{3}$.

No contexto das IST assintomáticas, o número de casos da Síndrome da Imunodeficiência Adquirida (AIDS) é subestimado. Assim, o encarceramento é uma oportunidade para o diagnóstico destas infecções na população prisional que sabidamente apresenta comportamentos de risco e acesso deficiente aos serviços de saúde ${ }^{2}$.

As IST possuem mais de 30 agentes etiológicos e a transmissão ocorre por contato sexual, via sanguínea e vertical (da mãe para o filho durante a gestação, parto e amamentação). Quanto ao prognóstico, algumas apresentam tratamento e cura enquanto outras são passíveis apenas de acompanhamento para minimização dos sintomas. Ressalta-se que as infecções apresentam elevadas taxas de incidência e prevalência e manifestam maiores complicações entre as mulheres ${ }^{3}$.

Ademais, possuir IST/AIDS afeta emocionalmente o indivíduo que vê no diagnóstico recebido muito além do que apenas uma doença. É para muitos o diagnóstico de morte, de estigma social, isolamento e elevado sofrimento mental, manifestado por depressão, ansiedade e baixa autoestima ${ }^{4}$.

Assim, o recebimento do diagnóstico de uma IST/ AIDS deve ser acompanhado por profissionais de saúde para aconselhamento, principalmente emocional. A enfermagem, por sua vez, desempenha importante papel na assistência integral das detentas, com foco na educação em saúde e estímulo à redução de riscos ${ }^{5}$.

Baseado no exposto, o presente estudo possui como objetivo: conhecer os riscos que caracterizam as detentas como um grupo susceptível a IST; revelar as reações frente ao diagnóstico positivo; e discutir a importância do aconselhamento em saúde.

\section{REVISÃo DE LITERATURA}

As IST/AIDS são passíveis de prevenção, entretanto, dados mostram que a incidência de casos aumenta em todo o mundo ${ }^{3}$. Além disso, nas populações vulneráveis e que apresentam comportamentos de risco o crescimento de casos é ainda mais rápido, a exemplo das mulheres em situação de reclusão ${ }^{1}$.

Como uma das IST de maior impacto, estima-se que a prevalência da infecção pelo Vírus da Imunodeficiência
Humana (HIV) e da AIDS nos presídios varia de 3 a $16 \%$. Tais valores são, por outro lado, subestimados. Muito presos são HIV positivo, porém, não diagnosticados².

Em relação à população carcerária feminina, o crescente número de IST relaciona-se a três fatores: individual, interpessoal e ambiental (socioeconômico e político). $\mathrm{O}$ aspecto individual diz respeito à fragilidade emocional, à baixa autoestima, ao consumo de drogas e às práticas sexuais inseguras. Ao passo que o interpessoal inclui violência doméstica e estupro; o ambiental diz respeito ao baixo nível de escolaridade, estigma social e desemprego ${ }^{6}$.

Nesse sentido, o diagnóstico de uma IST gera forte carga emocional nestas mulheres que além do sentimento de culpa, são expostas ao estigma, discriminação e violência, por motivos biológico, psicossocial e cultural ${ }^{3}$.

Portanto, a equipe de saúde possui importância no contexto da descoberta do diagnóstico e tratamento, bem como no acompanhamento emocional destas mulheres. Além disso, a enfermagem desenvolve ações com foco nas atividades de educação em saúde e redução de riscos ${ }^{5}$.

\section{Metodologia}

O presente estudo é de cunho descritivo com abordagem qualitativa. Descritivo por retratar e analisar os elementos como eles se apresentam, constituindo uma análise profunda da realidade estudada; de abordagem qualitativa por ter o ambiente como fonte direta dos dados, e focalizar a abordagem no processo e seu significado ${ }^{7}$.

A pesquisa teve como cenário uma penitenciária feminina localizada em Teresina-Piauí. Participaram do estudo nove presidiárias conforme os seguintes critérios de inclusão: estar infectada por uma IST/AIDS e ter conhecimento do diagnóstico através dos resultados de exames realizados pelo Centro de Testagem e Aconselhamento (CTA).

A coleta dos dados, mediante entrevista semiestruturada, ocorreu no período de agosto e setembro de 2010, foi utilizado um formulário semiestruturado. Foram pesquisados dados socioeconômicos (faixa etária, estado civil, escolaridade, renda) e hábitos referentes a etilismo/tabagismo/uso de drogas ilícitas. Além disso, foram feitas indagações em relação às reações diante do diagnóstico de IST/AIDS e ao aconselhamento realizado pela equipe de saúde. As falas foram gravadas e imediatamente transcritas, em seguida foi realizada a análise e interpretação dos dados.

Vale registrar que foi mantido o anonimato das entrevistas, cujos depoimentos forma identificados pela letra $\mathrm{E}$ e respectivo número de ordem de participação no estudo.

Nesse contexto, os registros foram interpretados com base no método de análise de conteúdo, que envolve três fases: pré-análise dos dados, classificação das ideias em categorias e interpretação dos dados ${ }^{8}$. Os discursos foram analisados a partir de leitura inicial, e escolha das informações de acordo com a exaustividade, representa- 
tividade do conteúdo e pertinência à temática estudada, com foco ao caráter homogêneo das informações. Em seguida foram classificados e agregados em unidades de registro, com posterior formulação de duas categorias, a saber: caracterização das participantes e dos comportamentos de risco e; vivências frente ao diagnóstico de IST/AIDS e importância do aconselhamento. Por fim realizou-se a inferência e interpretação dos resultados, através da justaposição das categorias ${ }^{9}$.

O estudo obedece aos preceitos éticos contidos na Resolução no196/1996, do Conselho Nacional de Saúde, vigente à época da realização do estudo, tendo o projeto recebido aprovação pelo Comitê de Ética da Universidade Federal do Piauí com o número do CAEE: 4891.0.000.044-10. Aos participantes, foi garantido o sigilo das informações e os devidos esclarecimentos sobre o estudo e seus objetivos através do Termo de Consentimento Livre e Esclarecido (TCLE).

\section{RESULTADOS E DISCUSSÃo}

Os achados deste estudo estão dispostos em duas categorias. A primeira caracteriza as nove participantes (faixa etária, nível de escolaridade, ocupação e renda) e discute os comportamentos de risco que as tornam vulneráveis às IST/AIDS. Na segunda categoria são apresentadas as vivências das detentas frente ao diagnóstico positivo para uma IST/AIDS e reforça a importância do aconselhamento em saúde.

\section{Caracterização das participantes e dos comportamen- tos de risco}

Participaram desta pesquisa, nove mulheres em situação de reclusão sabidamente portadoras de uma IST/AIDS, cuja faixa etária variou de 22 a 34 anos. No que se refere à escolaridade, apenas uma era analfabeta, as demais haviam concluído o ensino fundamental e o ensino médio, em igual proporção.

O baixo grau de instrução relaciona-se ao aumento da vulnerabilidade às IST/AIDS por induzir a manutenção de comportamentos de risco. Nesse sentido, segundo estudo desenvolvido nos Estados Unidos da América, a população carcerária com baixa renda e nível de escolaridade insatisfatório está mais susceptível ao HIV ${ }^{10}$.

A renda média mensal das participantes variou em torno de um salário mínimo e as ocupações mais citadas foram respectivamente: doméstica, profissional do sexo e feirante. A maior parte delas era solteira, e as demais possuíam união estável.

Infere-se, entretanto, que a ausência de um parceiro sexual fixo não é definidora de risco. A exemplo, uma pesquisa norte americana revelou que a maioria das presidiárias portadoras de IST/AIDS possuíam companheiro estável ${ }^{6}$.

A manutenção de relações sexuais seguras é, portanto, mais importante do que a quantidade de parcerias sexuais. Nesse sentido, um relacionamento estável ou de longa data não exclui o risco de adquirir uma IST/AIDS e, portanto, mantêm-se a necessidade da prevenção.

Além disso, o falso sentimento de segurança que as mulheres afirmam sentir ao apaixonar-se coloca em risco a sua saúde sexual e, pelo medo de perder o companheiro, muitas vezes não insistem no uso do preservativo ${ }^{6}$, de forma que muitas mulheres, mesmo cientes, se expõem ao risco.

Eu tinha relação só com o meu marido (sem camisinha). Confiava nele e nunca pensei que eu pudesse pegar uma IST (E8).

Eu confiava no meu marido, ficava com ele sem camisinha (E9).

Meu marido é soropositivo. Quando eu o conheci, ele já era. Não usávamos camisinha. Só isso ... pra que pior? (E2).

Quando questionadas sobre os comportamentos de risco vivenciados, as mulheres entrevistadas citaram a múltipla parceria sexual e o envolvimento com drogas, com ênfase para as práticas sexuais desprotegidas. $\mathrm{O}$ uso incomum de preservativo durante as relações sexuais também foi evidenciado em outros estudos ${ }^{2,11}$. Além disso, acrescenta-se que, na população carcerária, o aumento do número de casos de HIV também está relacionado ao uso de drogas e à presença de outras IST/AIDS ${ }^{12}$.

Grande parte das participantes afirmou ser etilista e/ou tabagista, além de admitir o uso de diversas drogas, com ênfase para o crack e maconha. O consumo de drogas é a principal barreira para a manutenção de práticas sexuais seguras entre mulheres. Além disso, a associação entre drogas e trabalho sexual coloca a mulher em posição vulnerável ao homem ${ }^{6}$.

Em relação às infecções, os diagnósticos mais frequentes foram, nesta ordem: tricomoníase, sífilis, HIV/AIDS e herpes. As mesmas IST/AIDS foram encontradas por um estudo realizado no Peru com 180 mulheres privadas de liberdade, por outro lado, as mais comuns foram: cancro mole - $71(42,3 \%)$ e vaginose bacteriana - $41(23,3 \%)^{11}$.

Outra investigação avaliou 355 detentos na Uganda e obteve resultados discordantes aos deste estudo, uma vez que, sífilis e HPV foram as infecções mais comuns $(18,2 \% \text { e } 9,1 \% \text {, respectivamente })^{13}$.

Dados norte-americanos são consoantes ao encontrado neste estudo e infere que a tricomoníase é a IST/AIDS mais comumente diagnosticada entre mulheres presidiárias, além de aumentar a probabilidade de transmissão do HIV ${ }^{14}$.

No Brasil, um estudo realizado com 3.362 presos de 12 prisões do Estado do Mato Grosso do Sul destacou que 394 (12\%) deles relataram história pregressa de IST/AIDS. Além disso, a sorologia para sífilis foi positiva em 88 (17\%) mulheres e 272 (9,5\%) homens. Quanto 
ao HIV, menos de $50 \%$ dos participantes nunca haviam sido testados e 54 presos tiveram resultado positivo, dos quais 34 desconheciam o diagnóstico ${ }^{2}$.

Em relação ao estudo brasileiro, anteriormente, mencionado, reforça-se o perigo associado às IST assintomáticas e evidencia a importância dos exames admissionais realizados nos presídios, visto que o encarceramento é uma importante oportunidade de diagnóstico e de quebra da cadeia de transmissão.

Diante da alta prevalência do diagnóstico de IST/AIDS em ambiente prisional, tanto no Brasil como em outros países, a identificação das características sociodemográficas e dos comportamentos de risco assumidos pelas detentas são essenciais para o entendimento desta problemática. Além disso, o encarceramento também possibilita o diagnóstico, tratamento e acompanhamento destas infecções.

\section{Vivências frente ao diagnóstico de IST/AIDS e impor- tância do aconselhamento}

Diante do elevado quantitativo de portadoras de IST/AIDS privadas de liberdade, a admissão prisional é tida como uma importante oportunidade para o diagnóstico precoce e tratamento destas infecções ${ }^{15}$.

A maioria das entrevistadas revelou ter recebido o diagnóstico da IST/AIDS durante a admissão na instituição prisional, o que reforça a importância da realização dos exames admissionais como forma de diagnóstico precoce.

Foi quando eu fiz um exame aqui. Foi assim que eu cheguei (E1).

Além disso, nesse momento de descoberta do diagnóstico, destaca-se o valor da equipe de saúde que atua no aconselhamento pré e pós teste. $\mathrm{O}$ diagnóstico de uma IST/AIDS pode gerar impactos na qualidade de vida dessas mulheres que, muitas vezes, desconhecem o real significado do diagnóstico, se expõem a momentos de crise emocional e manifestam reações diversas.

Diante do diagnóstico positivo para uma IST/AIDS, as mulheres manifestam com maior frequência: sentimentos de vergonha, tristeza e medo, resultantes da falta de informação, estigma e principalmente pela direta relação com o comportamento sexual ${ }^{16}$. Além disso, é comum o receio do julgamento/rejeição familiar, mal-estar e confusão diante do diagnóstico recebido, como citado nas falas das participantes descritas a seguir.

Fiquei muito triste, fiquei péssima. Eu fiquei muito constrangida, com medo de contar pra a minha família (E4).

Eu me senti mal, apesar de ter cura, mas a gente se sente mal (E6).

Estou com medo da AIDS, do HIV [...] a minha cabeça, na verdade, está confusa, porque eu fiquei espantada com isso (E7).

Além dos sentimentos iniciais de medo, confusão e vergonha, muitas mulheres se culpabilizam e, diante das incertezas sobre o diagnóstico, praticam atos contra a própria vida ${ }^{5}$. Observa-se, nos depoimentos, que o possível diagnóstico de uma infecção incurável provoca nas mulheres o desejo da morte.

Senti que eu era responsável. Eu entrei na chuva e sabia que ia me molhar (E2).

Fiz todo tipo de exame e deu sífilis, e eu tentei me matar. Eu tomei vários tipos de remédio, fiquei desesperada, pensei que fosse morrer. Eu fiquei desesperada, pensei que eu fosse morrer, que não tivesse cura, que fosse assim tipo a AIDS, uma coisa ruim [...] eu preferia morrer se não tivesse cura (E9).

Em outros casos, as mulheres atribuem ao parceiro a contaminação adquirida, já que, o fator determinante para o não uso de preservativos é a justificativa de confiança em uma relação monogâmica ${ }^{17}$. Nesse sentido, o relacionamento com o parceiro sexual também é prejudicado, surgem sentimentos de ira, revolta e desconfiança de traição ${ }^{5}$.

Mas me conformar, me conformar mesmo, eu não me conformei não. Porque a pessoa não se conforma com uma coisa dessa não. Aí eu estou com raiva dele porque se eu peguei, foi dele. Porque ele estava me' metendo chifre'. Só deve ter sido dele (E1).

Assim, a partir da análise das entrevistas, percebe-se que após o diagnóstico de uma IST/AIDS as mulheres transcorrem diferentes fases e além de tristeza e raiva observa-se o sentimento de barganha, quando estas confiam à fé o poder da cura.

Mas, aí estou aqui lutando, fazendo o tratamento. Está chegando aí a vacina. Eu espero, com fé em Deus, que ela seja alcançada para eu me curar (E4).

Mas, com fé em Deus, quando eu sair daqui vou procurar meios de me cuidar [...] vou procurar uma pessoa de bem para eu morar com ela sem precisar fazer programa novamente (E6).

Mas eu sempre tenho fé. Eu vencerei todos os meus obstáculos. Isso é mais um degrau que eu tenho que subir, é mais um cisco que caiu no meu olho e eu tenho que tirar (E7).

Ademais, foram observados dois desfechos principais referentes ao prognóstico da infecção. Em relação a IST curáveis, as detentas revelaram alívio perante a certeza de cura; enquanto as diagnosticadas com infecções incuráveis manifestaram tentativa de conformação com o diagnóstico.

Pensei que era outra coisa, mas a enfermeira disse para eu ficar despreocupada que era coisa pequena, tinha remédio para matar a doença (E5).

Normal, porque eu acho que é uma doença normal. Não é uma coisa de outro mundo[...] Até porque eu não tinha sintoma nenhum. Porque às vezes dá ferida, mas eu nunca tive. Aí eu fiz o tratamento (E3).

Mas eu não posso fazer nada, porque eu não tenho como curar, eu vou fazer o quê? (E1).

Por meio das falas apreende-se ainda o valor do sigilo na comunicação do diagnóstico e a importância das orientações sobre a infecção adquirida e respectivas opções de tratamento. 
Foi a enfermeira que me contou. Ela me chamou numa sala sozinha e me contou. Porque uma coisa dessas daí o povo tem preconceito (E1).

Foi a assistente social, ela mandou me chamar numa salinha reservada (E2).

O médico disse para mim que não era uma coisa muito grave, só se a gente não fizesse tratamento, aí eu fiquei numa boa (E5).

O aconselhamento pré e pós teste é uma etapa importante no cuidado ao paciente com suspeita ou diagnóstico de IST/AIDS e, apesar de ser negligenciada por muitos profissionais de saúde ${ }^{18}$, a maioria das detentas afirmou ter recebido o diagnóstico e informações sobre a infecção (formas de transmissão e tratamento), em sala reservada, pela enfermeira da instituição prisional. O médico e a assistente social também foram responsáveis pela informação do diagnóstico de algumas delas.

$\mathrm{O}$ apoio da equipe de saúde tem o objetivo de promover melhorias na saúde sexual, não apenas da mulher, mas do casal. A inclusão do parceiro promove o enfrentamento da reexposição a fatores de risco $^{17}$. Além disso, o apoio familiar e os grupos de apoio dentro dos presídios auxiliam a aceitação do tratamento e fortalecimento emocional destas mulheres ${ }^{16}$.

Importante ressaltar que, para as detentas, essas intervenções representam oportunidades, uma vez que, caso estivessem em regime de liberdade, raramente teriam a oportunidade de recebê-las. Uma pesquisa, realizada no Estado do Paraná mostrou que as reclusas recebem uma assistência integral da equipe de enfermagem, com direito a exames e tratamentos, além de apoio psicológico e acompanhamento do estado nutricional ${ }^{19}$.

Em conjunto às intervenções citadas, devem ser fornecidas informações sobre os comportamentos de risco, formas de prevenção e rastreio para IST/AIDS. A conscientização em relação às formas de transmissão favorece a saúde das próprias detentas e a de terceiros, pois é elevada a transmissão e propagação de IST/AIDS tanto durante o período de reclusão como a soltura ${ }^{20}$.

Ela [enfermeira] falou também para eu não me envolver com ninguém aqui dentro, porque às vezes há pessoas que tem [doenças] e não sabe. Aí esse tempo todo eu não me envolvo mais com ninguém. Eu estou só (E3).

As atividades de aconselhamento são indispensáveis durante a fase de diagnóstico de uma IST por minimizar os sentimentos vivenciados, e o encarceramento é uma oportunidade para a atuação profissional junto às detentas, ao passo em que possibilita o diagnóstico e tratamento de infecções até então não diagnosticadas.

\section{CONCLUSÃo}

Os principais comportamentos de risco assumidos pelas participantes do estudo foram o uso de drogas ilícitas, a múltipla parceria sexual e práticas sexuais desprotegidas.
Além disso, outros fatores de risco foram identificados como a baixa escolaridade, tabagismo e etilismo.

Quanto às reações diante do diagnóstico positivo para um IST/AIDS, estiveram presentes nas falas das detentas os sentimentos de tristeza, medo, mal-estar, confusão, receio do julgamento/rejeição familiar, raiva do companheiro e comportamento de barganha. Destaca-se que a resolução do momento de crise assumiu dois caminhos distintos, consoante ao status da IST adquirida: curável ou incurável. Para o primeiro grupo, prevaleceu o sentimento de alívio enquanto para o outro, uma tentativa de conformação com o diagnóstico.

Ainda de acordo com as entrevistadas, o aconseIhamento diante do diagnóstico positivo foi realizado predominantemente pela enfermagem e tal atividade mostrou-se decisiva para as detentas ao fornecer suporte emocional, sanar dúvidas sobre a IST adquirida e respectivas opções de tratamento, além de auxiliar na prevenção de infecções futuras.

Baseado no exposto, os objetivos do estudo foram alcançados e tem-se como limitação a não generalização dos resultados, considerando o número limitado de participantes e o tema íntimo, difícil de ser discutido, que leva certas mulheres ao receio de expressar seus sentimentos.

\section{REFERÊNCIAS}

1. Ministério da Justiça (Br). Departamento Penitenciário Nacional. Levantamento nacional de informações penitenciários: relatório. Brasília (DF): Ministério da Justiça; 2014.

2. Sgarbi RV, Carbone Ada S, Paião DS, Lemos EF, Simionatto S, Puga MA et al. A cross-sectional survey of HIV Testing and prevalence in twelve Brazilian Correctional Facilities. PLoSONE. 2015; 10(10): 1-12.

3. Ministério da Saúde (Br). Secretaria de Ciência, Tecnologia e Insumos Estratégicos. Protocolo clínico e diretrizes terapêuticas: infecções sexualmente transmissíveis. Relatório de recomendação. Brasília (DF): Ministério da Saúde; 2015.

4. Brinkley-Rubinstein L. Understanding the effects of multiple stigmas among formerly incarcerated hiv-positive African american men. AIDS Education and Prevention. 2015; 27(2): 167-79. 5. Jackson LJ, Roberts TE. Conceptualising quality of life outcomes for women participating in testing for sexually transmitted infections: A systematic review and meta-synthesis of qualitative research. Social Science \& Medicine. 2015; 143: 162-70.

6. Fogel Cl, Gelaude DJ, Carry M, Herbst JH, Parker S, Scheyette A et al. Context of risk for HIV and sexually transmitted infections among incarcerated women in the South: individual, interpersonal, and societal factors. Women \& Health. 2014; 54(8): 694-711. 7. Prodanov CC, FREITAS EC. Metodologia do trabalho científico: métodos e técnicas da pesquisa e do trabalho acadêmico. 2a ed. Novo Hamburgo (RS): Feevale; 2013.

8. Silva AH, Fossá MIT. Análise de conteúdo: exemplo de aplicação da técnica para análise de dados qualitativos. Qualitas. 2015; 16(1): 1-14.

9. Cavalcantes RB, Calixto P, Pinheiro MMK. Análise de conteúdo: considerações gerais, relações com a pergunta de pesquisa, possibilidades e limitações do método. Inf \& Soc Est. 2014; 24 (1): 13-8. 10.Wang EA, McGinnis KA, Long JB, Akgün KM, Edelman EJ, Rimland $D$ et al. Incarceration and health outcomes in HIV-infected patients: the impact of substance use, primary care engagement, 
and antiretroviral adherence. Am J Addict. 2015; 24(2): 178-84. 11. Garaycochea MC, Pino R, Chávez I, Portilla JL, Miraval ML, Arguedas $\mathrm{E}$, et al. Infecciones de transmisión sexual em mujeres de um establecimiento penitenciario de Lima, Perú. Rev Peru Med Exp Salud Publica. 2013; 30(3): 423-7.

12. Azbel L, Wickersham JA, Wegman MP, Polonsky M,Suleymanov $\mathrm{M}$,Ismayilov $\mathrm{R}$ et al. Burden of substance use disorders, mental illness, and correlates of infectious diseases among soon-to-be released prisoners in Azerbaijan. Drug Alcohol Depend. 2015; 151(1): 68-75

13. Katusiime C, Schlech WF 3rd, Parkes-Ratanshi R, Sempa J, Kambugu A. Characteristics of sexually transmitted infections among high-risk HIV-positive patients attending an urban clinic in Uganda. Journal of the International Association of Providers of AIDS Care. 2016; 15(1): 36-41.

14. Nijhawan AE, Chapin KC, Salloway R, Andrea S, Champion J, Roberts $\mathrm{M}$ et al. Prevalence and predictors of Trichomonas infection in newly incarcerated women. Sex Transm Dis. 2012; 39(12): 1-14. 15. Haley DF, Golin CE, Farel CE, WohI DA, Scheyett AM, Garrett JJ et al. Multilevel challenges to engagement in HIV care after prison release: a theory-informed qualitative study comparing prisoners' perspectives before and after community reentry. BMC Public Health. 2014; 14: 1-15.

16. East L, Jackson D, O'Brienc L, Peters K. Being diagnosed with a sexually transmitted infection (STI): sources of support for young women. Contemporary Nurse. 2015; 50(1): 50-7.

17. Reid AL, Niccolai LM, Gordon DM, Divney AA, Kershaw TS Associations of a sexually transmitted disease diagnosis during a relationship with condom use and psychosocial outcomes: (short) windows of opportunity. Am J Community Psychol. 2013; 51(3-4): 510-9.

18. Wachira J, Naanyu V, Genberg B, Koech B, Akinyi J, Kamene R et al. Health facility barriers to HIV linkage and retention in Western Kenya. BMC Health Services Research. 2014; 14(646): 1-8.

19. Camargo JP, Rutkoswki FP, Borba EO, Neves EB. O perfil das detentas HIV positivo de uma penitenciária estadual do Paraná, Brasil. J Health Sci Inst. 2012; 30(4): 369-76.

20. Mor Z, Eisenberg JR, Grottod I, Tishler-Aurkin D. HIV/AIDS prevalence in Israeli prisons: is there a need for universal screening? Journal of Public Health Policy. 2015; 36(4): 484-90. 